九州大学学術情報リポジトリ

Kyushu University Institutional Repository

\title{
Analysis of 3D Printed Stack in Thermoacoustic Cooling
}

Muhammad Nazmi Hadi Roslan

School of Mechanical Engineering, Faculty of Engineering, Universiti Teknologi Malaysia

Nor Atiqah Zolpakar

Dept. of Manufacturing Tech., Faculty of Engineering Technology, Universiti Malaysia Pahang

Normah Mohd-Ghazali

School of Mechanical Engineering, Faculty of Engineering, Universiti Teknologi Malaysia

Fat imah Al-Zahrah Mohd Saat

Faculty of Mechanical Engineering, Universiti Teknikal Malaysia

https://doi.org/10.5109/4372269

出版情報 : Evergreen. 8 (1)，pp.131-137，2021-03. Transdisciplinary Research and Education Center for Green Technologies, Kyushu University

バージョン :

権利関係 : 


\title{
Analysis of 3D Printed Stack in Thermoacoustic Cooling
}

\author{
Muhammad Nazmi Hadi Roslan ${ }^{1}$, Nor Atiqah Zolpakar ${ }^{2}$, Normah Mohd-Ghazali ${ }^{3 *}$ \\ and Fatimah Al-Zahrah Mohd Saat ${ }^{4}$ \\ ${ }^{1,3}$ School of Mechanical Engineering, Faculty of Engineering, Universiti Teknologi Malaysia, 81310 UTM \\ Skudai, Johor, Malaysia \\ ${ }^{2}$ Dept. of Manufacturing Tech., Faculty of Engineering Technology, Universiti Malaysia Pahang, Malaysia \\ ${ }^{4}$ Faculty of Mechanical Engineering, \\ Universiti Teknikal Malaysia, 76100 Melaka, Malaysia
}

*Corresponding Author’s email: normah@mail.fkm.utm.my

(Received November 27, 2020; Revised March 5, 2021; accepted March 23, 2021).

\begin{abstract}
Inconsistencies in fabricated thermoacoustic stacks are due to the methods available to obtain the desired geometry and dimensions even under optimized design parameters. This paper presents performance results from stacks fabricated using 3D printing technology which minimizes the error, disposes of irregularities and can reduce production time. In this study, the performance of a thermoacoustic refrigerator was determined from measurements of the temperature difference across various 3D printed stack lengths fabricated. Experiments were done at $400 \mathrm{~Hz}$ frequency with different stack plate spacing and thickness, in a $21-\mathrm{mm}$ diameter resonator. Results show that a 0.7 $\mathrm{mm}$ stack plate spacing with a $0.5 \mathrm{~mm}$ plate thickness performed better compared to those with smaller spacing at the same thickness or with the same spacing but larger thickness. The outcomes of this study have shown the need for the fabrication technology to keep pace with optimized design to realize global efforts towards a sustainable environment.
\end{abstract}

Keywords: thermoacoustic refrigerator, performance, stack, 3D printing

\section{Introduction and background}

There have been many articles on the historical developments of hazardous refrigerants systems ${ }^{1}$. There have been as many, if not more, studies and reports completed and on-going on proven and suggested procedures and programs to manage and consequently, improve current, and future processes and systems to reduce our reliance on non-environmentally friendly refrigerants $2,3,4,5$. Although many improvements have been made, much effort is still needed towards achieving a sustainable environment far from the threat of global warming and ozone depletion. The refrigerants used in the cooling systems predominantly contribute to direct and indirect global warming 1,3,5). A thermoacoustic refrigerator (TAR) is getting more attention as an alternative environmentally friendly cooling system after a successful cooler introduces by Hofler in $1986^{(6)}$.

An interesting criterion of the TAR system is the working fluid used in the system. Instead of using hazardous refrigerants, TAR uses the noble gases as the working fluid ${ }^{7}$. The working principle of the system is based on the compression and rarefaction of gas particles as they oscillate in an enclosure. A system of solid walls places strategically in their path produced a temperature difference across the stack length over time. The solid walls are usually made of plates in the direction parallel to the flow of gas parcels. The coefficient of performance (COP) to date, however, is still low which restrains the practical application of the technology $8,9,10,11$ ).

The low COP is attributed mainly to the stack component design and fabrication. Wheatley et al. ${ }^{12}$ described that the best plate separation is between $2 \delta_{k}$ to $4 \delta_{k}$ where $\delta_{k}$ is the thermal penetration depth. Tijani and his team ${ }^{13)}$ investigated the stack optimal spacing for thermoacoustic refrigeration. Experiments with Mylar material were conducted to test the stack performance between these suggested ranges.

Based on experiments conducted by Tijani et al. ${ }^{13)}$, the solid wall separation significantly affected the performance even though the tested values were within the suggested values. Tijani et al. ${ }^{13)}$ claimed that the the stack plates should be separated at a distance of $3 \delta_{k}$ to obtain the optimum performance of the stack. Other researchers have reported their optimized stack separation slightly more or less. It has been generally concluded that the ideal separation distance between the solid walls should be between 2 to 4 thermal penetrations depths or boundary layers $\left(\delta_{k}\right)$ for the best stack performance in generating thermoacoustic effects ${ }^{13,14,15)}$.

Materials selection for a stack is constrained by the structural complexity of the stack geometry and the 
method of fabrication. The stack material is directly related to the structural geometry of the stack. The readymade square geometry is available by using off-the-shelf ceramic material because this structural material is massproduced for use in the automotive industries as exhaust filters. For other alternative geometries, they are generally made by hand - which involved a meticulous process - the most well-known material used to date is Mylar. Tasnim et al. ${ }^{16)}$ studied different materials like aluminum, copper, and reticulated vitreous carbon (RVC) in the form of a porous material, to examine the irreversible heat transfer in the stack. Other researchers like Picollo ${ }^{17)}$ investigated the usage of stainless steel as the stack material but the most common materials to date is still Mylar and ceramic. The stack should have high heat capacity but low thermal conductivity, ideal for temporary storage of heat without transferring the heat to other parts of the stack. These materials are still being used by researchers due to the availability of the materials as well as the stack manufacturability.

The latest material is that used by Zolpakar et al. ${ }^{18)}$ an ABS material for fabricating the stack by using a 3D printer. Even though the thickness and spacing did not follow previously reported optimization results ${ }^{19)}$, their experimental results showed that their $3 \mathrm{D}$ printed stack exhibited the best outcome. The consistency in the stack walls being fabricated by a machine was identified as the significant contributor to the good performance reported. Being the main component of the thermoacoustic system, the stack finished product has been dependent on the fabrication mechanism ${ }^{20}$. The system design generally starts with the setting of the desired temperature difference across the stack and a good performance indicator is represented by the lowest final temperature difference achieved or the lowest temperature at the cold end of the stack.

Reports have shown that the 3D printed stacks exhibited promising results compared to other fabricating method ${ }^{19,21)}$. However, many studies compared only the optimized stack made from a 3D printer with other optimized stacks with different fabricating methods. This paper presents outcomes obtained on the experiments to measure the performance of an optimized stack and nonoptimized stack in terms of the temperature difference measured, using the same fabricating method which is a $3 \mathrm{D}$ printing technology. The results presented here indicate the importance of the stack parameters design to be in tandem with current fabrication technology that keeps up with the theory of thermoacoustic cooling.

\section{Design Parameters of TAR}

There are four basic parts to the thermoacoustic refrigerator, they consist of an acoustic driver that generates pressure oscillations, a stack "system" made up of solid walls with spacings for gas parcels to pass through, hot and cold heat exchangers, and the resonator tube closed at the end. The design parameters of the stack such as the stack length, $L_{s}$, stack center position, $x_{s}$, and the cross-section, $A$, can affect the performance of the stack as well as the thermoacoustic refrigeration itself ${ }^{22}$. The design parameters are interdependent. With the presence of the stack, as the gas parcels move back and forth between the solid walls, a temperature difference can be established along the stack in the resonator tube. Performance of the stack that is considered good is characterized by a high coefficient of performance (COP) which is the ratio of the cooling power to the acoustic power at the stack. The normalized cooling power, $Q_{c n}$, and acoustic power, $W_{n}$, given by Tijani et al. ${ }^{13)}$ are:

$$
\begin{aligned}
& Q_{c n}=\frac{\delta_{k n} D^{2} \sin 2 x_{n}}{8 \gamma(1+\sigma) \Lambda} \times\left(\frac{\Delta T_{m n} \tan x_{n}}{(\gamma-1) B L_{s n}} \frac{1+\sqrt{\sigma}+\sigma}{1+\sqrt{\sigma}}-(1+\right. \\
& \left.\left.\sqrt{\sigma}-\sqrt{\sigma \delta_{k n}}\right)\right) \\
& W_{n}=\frac{\delta_{k n} L_{s n} D^{2}}{4 \gamma}(\gamma-1) B \cos ^{2} x_{n} \times \\
& \left(\frac{\left.\llbracket \Delta T)_{m n} \tan \llbracket x_{n}\right)}{B L_{s n}(\gamma-1)(1+\sqrt{\sigma}) \Lambda}-1\right)-\frac{\delta_{k n} L_{s n} D^{2}}{4 \gamma} \frac{\sqrt{\sigma} \sin ^{2} x_{n}}{B \Lambda}
\end{aligned}
$$

where $\Lambda$ is represented by

$$
\Lambda=1-\sqrt{\sigma \delta_{k n}+0.5 \sigma \delta^{2}{ }_{k n}}
$$

The performance of the stack unit has commonly been determined experimentally by measuring the lowest temperature recorded at the cold end of the stack or the temperature drop across the stack, $\Delta T_{m}$. These measurements were utilized in this paper. The parameters used in this study are listed in Table 1. For this study, air at atmospheric pressure is used as the working fluid in the thermoacoustic refrigerator. Although air has not been reported as a practical working fluid due to its availability and low cost making it as the most often used fluid in experiments involving analysis of relationships between parameters.

The system is aimed to achieve a temperature difference of $30^{\circ} \mathrm{C}$ by applying an operating frequency, $f$, of $400 \mathrm{~Hz}$ at atmospheric pressure. The experiment was conducted in air-conditioning room to maintain the room temperature. For the optimized stack, the stack length and center position has been determined based on the work of Zolpakar et al. ${ }^{19)}$, with the optimized outcomes of $L_{s}=$ $4 \mathrm{~cm}, x_{s}=4 \mathrm{~cm}$ and plate spacing, $2 y_{0}=0.36 \mathrm{~mm}$. The hot and cold heat exchangers are absent in this study because the objective here was to look at the effects of various 3D printed stacks on the temperature obtained at both ends of the stack and on the temperature difference achievable. 
Table 1. Dimensionless parameters for TAR system

\begin{tabular}{|c|c|c|}
\hline $\begin{array}{c}\text { Dimensionless } \\
\text { parameters }\end{array}$ & Dimensionless tack geometry & Fluid properties \\
\hline $\begin{array}{l}\text { Drive ratio: } \mathrm{D}=\mathrm{p}_{0} / \mathrm{p}_{\mathrm{m}} \\
\text { Cooling power: } \mathrm{Q}_{\mathrm{cn}}=\mathrm{Q}_{\mathrm{c}} / \mathrm{p}_{\mathrm{m}} \mathrm{aA} \\
\text { Acoustic power: } \mathrm{W}_{\mathrm{n}}=\mathrm{W} / \mathrm{p}_{\mathrm{m}} \mathrm{aA} \\
\text { Temperature difference: } \Delta \mathrm{T}_{\mathrm{mn}} \\
\quad=\Delta \mathrm{T}_{\mathrm{m}} / \mathrm{T}_{\mathrm{m}}\end{array}$ & $\begin{array}{l}\text { Stack length: } L_{s n}=k L_{s} \\
\text { Stack position: } x_{n}=\mathrm{kx} \\
\text { Blockage ratio/porosity: } B=y_{0} /\left(y_{0}\right. \\
\quad+l)\end{array}$ & $\begin{array}{l}\text { Density, } \rho=1.184 \mathrm{~kg} / \mathrm{m}^{3} \\
\text { Specific heat, } c_{p},=1007 \mathrm{~J} / \mathrm{kg} . \mathrm{K} \\
\text { Thermal Conductivity, } k=0.02551 \\
\text { W/m.K } \\
\text { Thermal Diffusivity, } \alpha=2.141 \times 10^{-5} \mathrm{~m}^{2} / \mathrm{s} \\
\text { Dynamic Viscosity, } \mu=1.849 \times 10^{-5} \\
\text { kg/ms } \\
\text { Kinematic Viscosity, } v=1.562 \times 10^{-5} \mathrm{~m}^{2} / \mathrm{s} \\
\text { Prandtl Number, } \operatorname{Pr}=0.7296\end{array}$ \\
\hline
\end{tabular}

\section{Experimental Setup}

The optimized stack parameters from the design of Zolpakar et al. ${ }^{19)}$ was selected; the stack length, the stack center position, and the stack plate separation gap. For the non-optimized stack, only the stack plate spacing and plate thickness were changed. Solidworks was used to complete the stack drawing and the specific dimensions were provided since it was fabricated using a $3 \mathrm{D}$ printer. The stack design used in the experiment is parallel plate stack with $0.36 \mathrm{~mm}$ stack spacing as proposed by Zolpakar et al. ${ }^{19)}$. However, due to the limited capability of the available $3 \mathrm{D}$ printer, the smallest thickness of the plate was $0.5 \mathrm{~mm}$ with the material being AcrylonitrileButadiene-Styrene (ABS) that has a thermal conductivity, $k=0.20 \mathrm{~W} / \mathrm{mK}$ and specific heat of $1470 \mathrm{~J} / \mathrm{kgK}$. Fig. 1(a) and (b) show the geometry of the stack and experimental layout for the experiment.

The experiment was conducted in air-conditioning room at range of room temperature $26^{\circ} \mathrm{C}$ to $28^{\circ} \mathrm{C}$. The experiment test rig consists of function generator to generate electrical signal and then the signal will be amplified using amplifier to the frequency set for the experiment. The frequency used in this experiment is 400 $\mathrm{Hz}$. Then, the electrical signal converted into wave signal by mid-range loudspeaker. The sound waves travelled in quarter resonator tube. The $21-\mathrm{mm}$ resonator was a quarter-wavelength resonator from an Acrylic material having its fundamental resonance frequency at $400 \mathrm{~Hz}^{21}$. At the end of the tube was a rigid end (aluminum reflector). The measurement of the temperatures was taken with thermistors. Three thermistors were installed in the resonator; at both end of stack and the third one is used to measure the room temperature. The temperature reading from thermistor will be transfer to computer by portable data acquisition model. For reliability, each experiment was repeated thrice. Data was only taken after the system reached steady state condition. The system can be said achieved steady state condition when there is no changed of temperature reading at cold end stack. There were three kinds of temperature that were recorded which is; the temperature of the surrounding $\left(T_{\text {Surr }}\right)$, the temperature at the hot end $\left(T_{H o t}\right)$, and the temperature at the cold end ( $\left.T_{\text {Cold }}\right)$ of the stack.

The stacks tested were an optimized stack with optimized parameters (Case 1), non-optimized stacks each with different plate gaps of $0.5 \mathrm{~mm}$ and $0.7 \mathrm{~mm}$ (Case 2 and 3 ) and non-optimized stacks each with different plate thickness of $0.7 \mathrm{~mm}$ and $1.0 \mathrm{~mm}$ (Case 4 and 5). A total of five stacks were investigated as listed in Table 2.

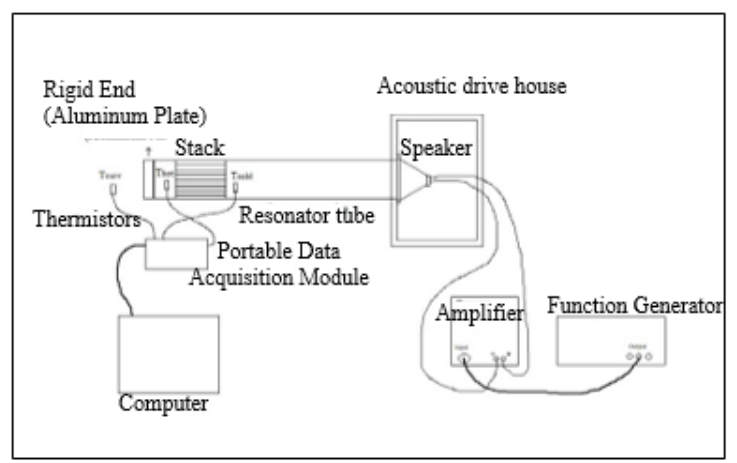

(b)

Fig. 1. (a) Geometry of the stack, (b) Experimental layout 
Table 2. Stack properties used in experiment

\begin{tabular}{|l|c|c|}
\hline Stack & Stack spacing & Stack thickness \\
\hline Case 1 & $0.36 \mathrm{~mm}$ & $0.5 \mathrm{~mm}$ \\
\hline Case 2 & $0.50 \mathrm{~mm}$ & $0.5 \mathrm{~mm}$ \\
\hline Case 3 & $0.70 \mathrm{~mm}$ & $0.5 \mathrm{~mm}$ \\
\hline Case 4 & $0.36 \mathrm{~mm}$ & $0.7 \mathrm{~mm}$ \\
\hline Case 5 & $0.36 \mathrm{~mm}$ & $1.0 \mathrm{~mm}$ \\
\hline
\end{tabular}

\section{Results and Discussion}

Fig. 2(a) shows the temperature recorded for the experiments to compare the optimized stack with the stacks with different plate spacing. The temperature difference obtained for Case 1,2 and 3 were $12.42{ }^{\circ} \mathrm{C}$, $6.09{ }^{\circ} \mathrm{C}$ and $18.54{ }^{\circ} \mathrm{C}$ respectively. The stack performance in terms of the temperature difference in each case shows that the stack from Case 3 has a better performance than the stack from Case 1 and 2 since the temperature difference obtained across the stack is bigger. The temperature difference obtained is unexpected. By comparing these three cases, Case 1 should have the highest temperature difference because it is the stack with the optimized parameters. However, the results obtained show that the stack from Case 3 has the highest temperature difference. This may due to the defect during the fabrication using $3 \mathrm{D}$ printer. $3 \mathrm{D}$ printer used solid material as ink then the material was melted to become liquid to print the geometry and then after printed process completed, the material will cool down and become solid again. During heating and cooling of the ink that also become the material for the stack, compression and expansion of the material happen and affect the final geometry of the stack. When the plate spacing of the stack is too close to each other, the gas parcels will have difficulties passing through the stack effectively mainly because of the viscous properties of the working fluid that is holding back the gas parcels from oscillating freely. Same goes if the spacing is too far apart, the heat interactions between gas bundles and the stack wall cannot happen successfully. The results were unexpected probably because of the size of the stack. In Zolpakar et al. ${ }^{19)}$ study, the size of the stack was much bigger than this experiment. The stack size was $36 \mathrm{~mm}$ while this experiment used a $21 \mathrm{~mm}$ stack. The optimization of the stack parameters was based on the $36 \mathrm{~mm}$ stack from their study. Since the stack used in this experiment was smaller, the optimized stack parameter may be different. In Fig. 2(a), it also shows that the highest hot temperature $\left(T_{H o t}\right)$, obtained was for the stack from Case 1 which is $38.91{ }^{\circ} \mathrm{C}$. Followed by Case 3 and 2, the hot temperature $\left(T_{H o t}\right)$ were $38.75{ }^{\circ} \mathrm{C}$ and $33.76{ }^{\circ} \mathrm{C}$ respectively. On the contrary, the lowest cold temperature $\left(T_{\text {Cold }}\right)$, recorded was for the stack from Case 3 which was $20.21{ }^{\circ} \mathrm{C}$. Meanwhile, the cold temperature $\left(T_{\text {Cold }}\right)$, for the stack from Case 1 and 2 were $26.49{ }^{\circ} \mathrm{C}$ and $27.67{ }^{\circ} \mathrm{C}$ respectively.
Fig. 2(b) shows the temperature recorded for the experiments to compare the optimized stack with the stacks with different plate thickness. The value of the temperature difference obtained for Case 1, 4 and 5 were $12.42{ }^{\circ} \mathrm{C}, 11.72{ }^{\circ} \mathrm{C}$ and $4.31{ }^{\circ} \mathrm{C}$ respectively. Looking at the temperature difference recorded between the stack ends, the performance of the stack in each case shows that the stack from Case 1 has a better performance than the stacks from Case 4 and 5. The temperature difference for each case is decreasing as expected. When the plate thickness is bigger with thinner spacings, the harder it is for gas molecules to pass through it. Some of the heat is also retained by the solid if it is thick instead of being transferred to the stack end. With thinner plates and larger spacings, the blockage ratio is lower and it produces a higher thermal performance. Based on Putra et al. ${ }^{24)}$ studies, more thin plates in a stack can increase the performance of the stack. Thinner plates and consequently accommodating more plates in the resonator could expose more active area for thermal interactions within the given resonator ensuring a faster rate of cooling. These results have also been supported by Rahpeima and Ebrahimi ${ }^{25}$. Based on Rahpeima and Ebrahimi ${ }^{25)}$, by increasing the thickness of the stack plates resulting in fewer number of plates with less exposed area for thermoacoustic effects, the fluid parcels will encounter more resistance from the thick solid walls during their oscillatory motion. Thus, viscous losses will increase.

Fig. 3 show the temperature difference achieved by the stack based on the number of stack plates in the stack. The number of plates obtained by simple calculation based on the stack spacing and thickness. The number of stack plates represents the surface area that experiences heat transfer process. Case 1 has highest number of plate, so it has highest surface area. The temperature difference for Case 1 is $12.42{ }^{\circ} \mathrm{C}$. Meanwhile, Case 3 that has 18 stack plates reached the highest temperature difference, $18.54{ }^{\circ} \mathrm{C}$. Even though Case 1 predicted to have best performance, these results obtained probability due to error during fabrication process and thermal losses that generated along the surface of stack. This error happens due to the 3D printing technology that involved expansion and compression process during heating and cooling process of the printing ink especially for the narrow dimension. Due to the constraint of the available 3D printer available, the thinnest stack achieved was $0.5 \mathrm{~mm}$. However, with a $0.5 \mathrm{~mm}$ plate thickness, the results obtained were considerably good for the thermoacoustic refrigerator system. From Fig. 2(b) also, the hot temperature $\left(\mathrm{T}_{\mathrm{Hot}}\right)$ was $36.55^{\circ} \mathrm{C}$ and $31.92{ }^{\circ} \mathrm{C}$ for Case 4 and Case 5 respectively. Meanwhile, the lowest cold temperature $\left(T_{\text {Cold }}\right)$, recorded was by stack from Case 4 which was $25.28^{\circ} \mathrm{C}$. On the contrary, the cold temperature $\left(T_{\text {Cold }}\right)$, for stack from Case 1 and 5 were $26.49^{\circ} \mathrm{C}$ and $27.31{ }^{\circ} \mathrm{C}$ respectively. 


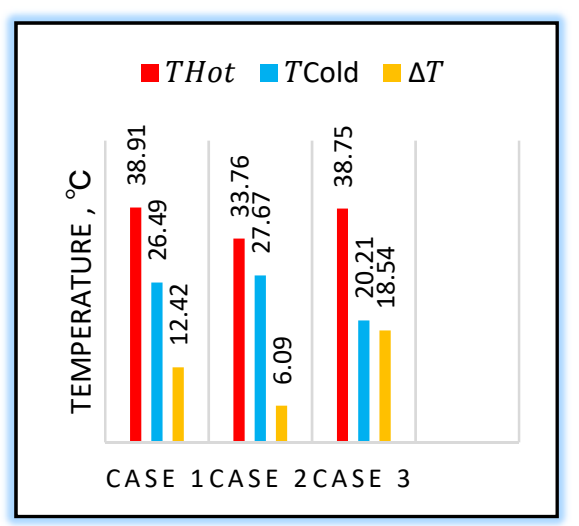

(a)

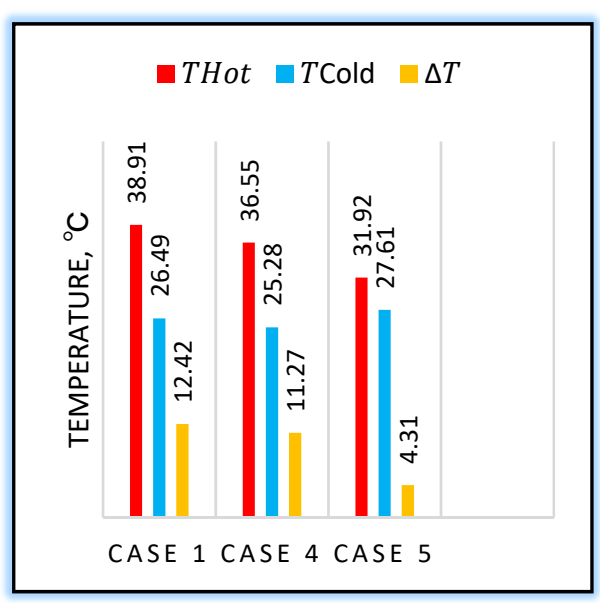

(b)

Fig. 2. (a) Temperatures for the stack with different plate spacing, (b) Temperatures for the stack with different plate thickness

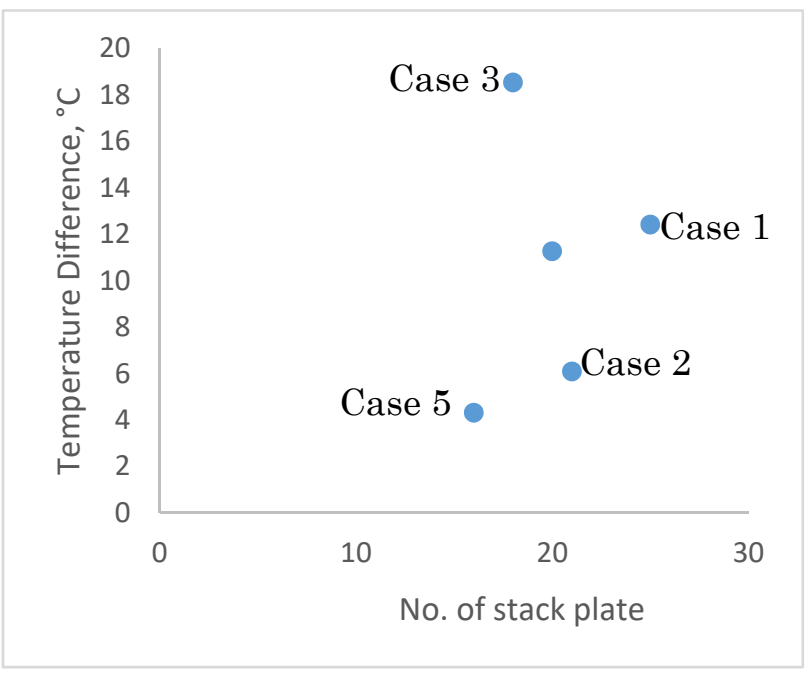

Fig. 3. Temperatures difference along the stack with number of stack plate in stack

\section{Conclusion}

The fabrication method used in the experiments had produced good results. The results have shown the importance of choosing the stack parameters. For the experiment to compare the stack plate spacing of optimized stack and non-optimized stack, the bigger plate spacing stack achieved a higher temperature difference compared to the other two stacks for a small diameter of the stack used in a thermoacoustic refrigerator. This is due to the optimized dimensions being taken from a study based on a larger diameter. With a smaller diameter, cooling effect is more significant. For the experiment comparing the stack plate thickness of optimized stack and non-optimized stack, the optimized stack achieved the highest temperature difference compared to other stacks used for this experiment. More thin plates are desirable for the stack in a thermoacoustic refrigerator. The performance of the thermoacoustic refrigerator is expected improve when fabrication technology can accommodate the optimized design requirements.

\section{Acknowledgements}

The authors acknowledge Universiti Teknologi Malaysia (UTM) and Universiti Malaysia Pahang (UMP) for the use of the research facilities and Ministry of Higher Education (FRGS/1/2019/TK10/UMP/03/2) for providing financial support to complete the study.

\section{Nomenclature}

$a$ Sound velocity $(\mathrm{m} / \mathrm{s})$

$A$ Area $\left(\mathrm{m}^{2}\right)$

$B$ Blockage ratio or porosity

$\mathrm{c}_{\mathrm{p}} \quad$ Specific heat of stack material (J/kg. K)

d Diameter (m)

$D$ Drive ratio

$f \quad$ Operating frequency $(\mathrm{Hz})$

$K$ Thermal conductivity of gas (W/m. K)

$k$ wave number $\left(\mathrm{m}^{-1}\right) \quad$ Case 4

$L_{s} \quad$ Length of stack (m)

$l \quad$ thickness of stack plate $(\mathrm{m})$

$p$ Pressure $(\mathrm{Pa})$

$Q \quad$ Cooling power (W)

$T$ Temperature (K)

$x \quad$ Center position of stack from driver (m)

$W \quad$ Acoustic power (W)

$y_{0} \quad$ Half plate spacing of stack (m)

Greek symbols

$\delta \quad$ Penetration depth (m)

$\gamma \quad$ Ratio of isobaric to isochoric specific heat 
$\rho \quad$ Density of stack material $\left(\mathrm{kg} / \mathrm{m}^{3}\right)$

$\sigma \quad$ Prandtl number

$\omega \quad$ Angular velocity $(\mathrm{rad} / \mathrm{s})$

$\mu$ : Dynamic viscosity (Pa. s)

$\Delta T \quad$ Temperature difference $(\mathrm{K})$

\begin{tabular}{ll}
\multicolumn{2}{l}{ Subscripts } \\
$c$ & Cool \\
$h$ & Hot \\
$k$ & Thermal \\
$n$ & Normalized \\
$m$ & Mean \\
$s$ & Stack \\
$v$ & Viscous \\
0 & Amplitude
\end{tabular}

\section{References}

1) P. Animesh, U., Kutub, T., Kyaw, S. Bidyut Baran, "Environmental Assessment and Characteristics of Next Generation Refrigerants", Evergreen, vol. 05, Issue 02, pp. 58-66 (2018).

2) S.A. Shaedi, N.M. GHazali, J.T. Oh, R. Ahmad, Y. Mohd-Yunos, "Entropy Generation Minimization of Two-Phase Flow in a Microchannel with Genetic Algorithm", Evergreen, vol. 06, Issue 01, pp. 39-43 (2019)

3) M.A. Islam, A. Pal, K. Thu, B.B. Saha, "Study on Performance and Environment Impact of Supermarket Refrigeration System in Japan", Evergreen, vol. 06, Issue 02, pp. 168-176 (2019)

4) P. Byrne, N. Putra, T. Mare, N. Abdallah, P. Lalanne, I. Alhamid, P. Estelle, A. Yatim, A.L. Tiffonnet, "Design of a Solar AC System Including a PCM Storage for Sustainable Resorts in Tropical Region", Evergreen, vol. 06, Issue. 02, pp. 143-148 (2019)

5) M.T. Kibria, M.A. Islam, B.B. Saha, T. Nakagawa, S. Mizuno, "Assessment of Environmental Impact for Air-Conditioning Systems in Japan Using HFC Based Refrigerants", Evergreen, vol. 06, Issue. 03, pp. 246253 (2019)

6) T.T., Hofler, Thermoacoustic Refrigerator Design and Performance. Doctor Philosophy, Physics department, University of California at San Diego. (1989).

7) A.T.A.M., De Waele, "Pulse-tube refrigerators: principle, recent developments, and prospects", Physica B: Condensed Matter, vol. 280, 479-482 (2000).

8) I., Girgin, M., Turker, "Thermoacoustic system as an alternative to conventional coolers". Journal of Naval Science and Engineering, 8:14-32 (2012).

9) T., Jin, J.L., Huang, Y. Feng, R., Yang, K., Tang, R., Radebagh, "Thermoacoustic prime movers and refrigerators: thermally powered engines without moving components", Energy, 93, 828-853 (2015.).

10) L.K., Tartibu, B., Sun, M.A.E., Kaunda, "Optimal Design of A Standing Wave Thermoacoustic
Refrigerator Using GAMS". Procedia Computer Science, vol. 62, 611-618(2015).

11) C.N., Emmanuel, A., Azrai, "Experimental Study on the Performance of the Thermoacoustic Refrigerating System". Applied Thermal Engineering. 29:26722679(2007).

12) J.C., Wheatley, T., Hofler, G.W., Swift, A., Migliori, "Understanding Some Simple Phenomena in Thermoacoustic with Applications to Acoustical Heat Engines". Am J Phys. 53:147 - 62(1985).

13) M.E.H., Tijani, J.C.H., Zeegers, A.T.A.M., De Waele, "Design of thermoacoustic refrigerators", Cryogenics, 42:49-57(2002).

14) B.G., Prashanta, S., Seetharamu, G.S.V.L., Narasimham, M.R., Praveen Kumar, "Effect of Stack Spacing on the Performance of Thermoacoustic Refrigerators Using Helium and Air as Working Substances". International Journal of AirConditioning and Refrigeration, vol. 27, no. 2, 1950016 (2019).

15) N.A., Zolpakar, N., Mohd-Ghazali, R., Ahmad, T., Mare, "Performance of a 3D-printed stack in a standing wave thermoacoustic refrigerator", Proceeding of the $8^{\text {th }}$ International Conference on Applied Energy, Beijing, China (2017).

16) S.H., Tasnim, S., Mahmud, R.A., Fraser, "Effect of Variation of Working Fluid and Operating Conditions on The Performance of Thermoacoustic Refrigerator". International Communications in Heat and Mass Transfer. 39:762-768(2012).

17) A., Picollo, "Optimization of Thermoacoustic Refrigerators Using Second Law Analysis". Applied Energy. 103:358-367(2013).

18) N.A., Zolpakar, N., Mohd-Ghazali, Comparison of a Thermoacoustic Refrigerator Stack Performance: Mylar Spiral, Celcor Substrates and 3D Printed Stacks. . International Journal of Air-Conditioning and Refrigeration. In Press. (2019).

19) N.A., Zolpakar, N., Mohd-Ghazali, R., Ahmad, "Experimental investigations of the performance of a standing wave thermoacoustic refrigerator based on multi-objective genetic algorithm optimized parameters", Applied Thermal Engineering, 100: 296-303(2016).

20) R.C., Dhuley, M.D., Atrey, "Investigation on a Standing Wave Thermoacoustic Refrigerator". International Crycooler Conference, Inc, Boulder, CO. (2011).

21) Ge Huan, Fan Li, Xia Jie, Zhang Shu-Yi, Tao Sha, Yang Yue-Tao, Zhang Hui, "Nonlinear Impedances of Thermoacoustic Stacks with Ordered and Disordered Structures". Chin. Phys. B. 23(7):074301(2014).

22) Z., Shaowei, "A new concept of cold resonator pulse tube refrigerator”, Energy, vol. 144, 10261036(2018).

23) K., Assawamartbunlue, C., Wantha, "Experimental Investigation on the Optimal Operating Frequency of 
a Thermoacoustic Refrigerator". International Journal of Mechanical and Mechatronics Engineer. 2(5):768-771 (2015).

24) N., Putra, D., Agustina, "Influence of stack plate thickness and voltage input on the performance of loudspeaker-driven thermoacoustic refrigerator". Journal of Physics: Conference Series, 423: 1250(2013).

25) R., Rahpeima, R., Ebrahimi, "Numerical investigation of the effect of stack geometrical parameters and thermo-physical properties on performance of a standing wave thermoacoustic refrigerator", Applied Thermal Engineering, vol. 149, 1203-1214 (2019). 